\title{
O ENSINO DA CULTURA INDÍGENA NAS ALDEIAS: O CASO DAS OFICINAS DE LETRAMENTO DO POVO TRUKÁ
}

\author{
TEACHING INDIGENOUS CULTURE IN VILLAGES: THE CASE OF \\ LITERACY WORKSHOPS OF THE TRUKÁ PEOPLE
}

Roberto Remígio Florêncio ${ }^{1}$

\begin{abstract}
Resumo: A história dos povos indígenas no Brasil, em especial os indígenas da região Nordeste, é importante para a compreensão das culturas autóctones (língua, história, religião) da formação da nação em seu reconhecimento enquanto povo miscigenado e pluricultural. Este escrito, de cunho contemplativo e analítico, busca analisar vivências e conteúdos pedagógicos na perspectiva interdisciplinar, buscando releituras para (re)construção e valorização da história e da cultura indígena no sertão baiano, através das práticas de letramento, dando ênfase à interseção dos saberes científicos com os saberes indígenas, proporcionando assim a discussão da construção do conhecimento. O estudo visa contemplar as vivências pedagógicas, as concepções e ações educacionais direcionadas para a construção e reconstrução de processos históricos dos indígenas através de metodologias lúdicas, com fins de promover a apreciação de diversas fontes metodológicas e subsidiar a leitura e a interpretação intercultural no contexto da Educação Escolar Indígena e o processo de letramento dos povos nativos no Semiárido Brasileiro.

Palavras-chave: Povos indígenas. Educação Escolar Indígena. Metodologia de Ensino.
\end{abstract}

Abstract: The history of indigenous peoples in Brazil, especially those of the Northeast region, is important for understanding the indigenous cultures (language, history, religion) of nation formation in their recognition as a mixed and pluricultural people. This contemplative and analytical writing seeks to analyze pedagogical experiences and contents in an interdisciplinary perspective, seeking re-readings for (re) construction and valorization of indigenous history and culture in the Bahian hinterland, through literacy practices, emphasizing the intersection of knowledge. with indigenous knowledge, thus providing the discussion of knowledge construction. The study aims to contemplate the pedagogical experiences, the conceptions and educational actions directed to the construction and reconstruction of historical processes of the indigenous through playful methodologies, with the purpose to promote the appreciation of diverse methodological sources and to subsidize the reading and the intercultural interpretation in the context of. Indigenous School Education and the literacy process of native peoples in the Brazilian Semiarid.

Keywords: Indigenous peoples. Indigenous School Education. Teaching Methodology.

\section{INTRODUÇÃO}

O estudo da cultura dos povos indígenas no Brasil, em especial dos indígenas do Nordeste brasileiro, é de suma importância para a compreensão do processo da formação da nação brasileira. No semiárido nordestino, em especial, no sertão pernambucano, encontram-se vários povos

\footnotetext{
${ }^{1}$ Doutorando em Educação - PPGE/UFBA; Mestre em Educação e Cultura (UNEB); Licenciado em Letras (UPE) e em Pedagogia (UNEB). Professor do IF Sertão - PE.
} 
indígenas em processo de reinvindicação de reconhecimento étnico, movimento marcado pela ressignificação ou reinvenção de etnias já existentes ou por novas identidades, processo denominado etnogênese (OLIVEIRA, 1993, 2014).

Esses povos têm empreendido lutas constantes pela afirmação de suas identidades étnicas, em um complexo processo que envolve questões de auto-reconhecimento e autoafirmação identitária, bem como a preservação do seu território, da sua história, da sua cultura e língua, fatores fundamentais para valorização do povo indígena. Nesta perspectiva, faz-se necessário discutir a aplicabilidade da Lei 11.645/08, focando na relação dos diversos saberes científicos com os saberes indígenas, incluindo a temática indígena no universo educacional nos campos das áreas das Ciências, "proporcionando e ampliando as discussões sobre saberes pertencentes a povos culturalmente distintos do pensamento hegemônico ocidental" (SILVA, 2011).

Este estudo contempla as diversas disciplinas que compõem o currículo escolar, buscando a interface entre o conhecimento didático-pedagógico aliado ao conhecimento dos povos indígenas, a fim de contribuir para a maior compreensão do processo histórico dos grupos indígenas do Sertão do Nordeste, buscando perceber como foram implementadas as políticas de colonização na região, que teve como consequência o desencadeamento de um processo de descaracterização precoce dos sinais que os diferenciavam da população não-indígena, se comparados aos grupos étnicos habitantes de outras regiões do país (SILVA, 1998, 2011; OLIVEIRA, 1993, 2014).

\section{A PESQUISA}

No intuito de facilitar, ou mediar, a compreensão das relações entre ensino e aprendizagem na percepção de construção e reconstrução do conhecimento, este estudo tem o objetivo de focalizar as questões de linguagem e registros de produção do conhecimentos histórico, sociocultural numa determinada temporalidade e num contexto social, possibilitando espaços e diversos olhares sobre o conhecimento escolar, acreditando que o letramento intercultural está presente nas escolas das aldeias de forma cristalizada e includente. Em todas as aulas assistidas nas escolas indígenas da região do semiárido pernambucano, especificamente no submédio São Francisco, foi possível constatar a presença das metodologias didáticas abordadas neste estudo: voltadas para a multiculturalidade, o bilinguismo e a Educação Escolar Indígena (FLORÊNCIO, 2016), a partir das análises baseadas nos estudos de letramento (STREET, 2010) e de hibridismo cultural (GEERTZ, 2010; CANCLINI, 2010).

Nas metodologias e instrumentos de trabalho, os professores utilizam-se de diversos recursos pedagógicos, incluindo a música e a literatura como elementos motivadores e de reflexão, 
especialmente na leitura e na produção de poemas, contos (narrativas) e cordéis. Percebeu-se a utilização da música como fonte para o ensino da cultura indígena na perspectiva apontada pela Professora Circe Bittencout, que ressalta:

Existe certa facilidade em usar a música para despertar interesse, o problema que se apresenta é transformá-la em objeto de investigação. Ouvir música é um prazer, um momento de diversão, de lazer, o qual, ao entrar em sala de aula, se transforma em uma ação intelectual (BITTENCOURT, 2005, p. 156).

A proposta da música como fonte metodológica relaciona-se com a concepção da música produzida num determinado contexto histórico-social e didático, de acordo com Kátia Maria Abud que "propõe um trabalho didático, no qual as letras de músicas populares sejam colocadas como evidências de fatos históricos" (ABUD, 2005, p. 132). E ainda perceber a música e o cinema como "fontes audiovisuais e musicais em suas estruturas internas de linguagem e seus mecanismos de representação da realidade, analisando, a partir daí, sua condição de 'testemunho' de uma dada experiência histórica e social" (NAPOLITANO, 2006, p. 112).

A proposta e utilização de filmes, poemas, contos e cordéis têm o intuito de proporcionar aos alunos a convivência com diversas formas literárias, o que possibilitará aos alunos contato com fontes diferentes do formato da escrita encontrada nos livros didáticos, a partir do exercício da análise dos discursos dos poetas diante dos acontecimentos. Desse modo, músicas, poemas, contos e cordéis, podem representar uma nova linguagem para o ensino a partir das narrativas que descrevam a cultura indígena. Essas expressões podem também, possibilitar aos alunos a elaboração de conceitos e significados, na compreensão de temporalidades, (re)significados de fatos históricos, socioculturais numa relação entre presente-passado.

Para direcionar propostas de ensino às escolas indígenas de Truká, foram desenvolvidas Oficinas Interdisciplinares de Letramento Intercultural durante o desenvolvimento da pesquisa do curso de mestrado do Programa de Pós-graduação em Educação, Cultura e Territórios Semiáridos, PPGESA, da Universidade do Estado da Bahia - UNEB, concluído em 2016. O principal objetivo foi o de criar espaços de discussão e reflexão acerca de possibilidades de fontes para o ensino da cultura indígena através da utilização de diferentes recursos metodológicos, enriquecendo a leitura plural do objeto de estudo, em suas tantas dimensões, material e imaterial. Dessa forma, foi proposto o uso de recursos metodológicos como música e literatura (poemas, cordel, contos etc.), a fim de compreender os diferentes sentidos culturais, estéticos e ideológicos sobre a cultura (História, Língua, Religião etc) dos povos indígenas no Brasil. A concepção das oficinas teve como objetivo comtemplar vivências pedagógicas aliadas a saberes pertinentes ao currículo escolar, às concepções e ações educacionais direcionadas à construção e reconstrução dos processos 
históricos indígenas através da música, filme, poema, contos e cordel, contribuindo para a (re)construção das narrativas indígenas, contextualizando o período histórico e a produção cultural, proporcionando aos alunos a apreciação de diversas fontes metodológicas a fim de subsidiar a leitura e a interpretação da história e cultura indígena.

Os procedimentos metodológicos são focados nas ações desenvolvidas inicialmente pelo professor orientador em sala de aula, sobre o conteúdo didático da cultura indígena brasileira.

Os professores-alunos para contemplar os objetivos definidos em grupos de discussão, selecionaram as músicas, filmes, poemas, contos e cordéis. O planejamento e a execução da Oficina aconteceram, em datas definidas pela Coordenação do Curso, com a anuência do professor orientador e dos professores-alunos.

Os professores-alunos envolvidos no projeto foram avaliados através da participação no desenvolvimento das atividades apresentadas em sala de aula, da execução da Oficina e da produção de relatos de experiências vivenciadas durante a execução da atividade.

\section{O LÓCUS DA PESQUISA}

O grupo étnico que contemporaneamente se reconhece como Truká habita uma região denominada Submédio São Francisco, localizada entre o Lago de Sobradinho e as barragens de Paulo Afonso, na Bahia, onde estão localizadas as quatro aldeias do povo indígena que foi expulso de suas terras durante o período de colonização, marcadamente entre os séculos XVIII e XIX. Com uma população estimada para 2017 em 3.640 índios (IBGE, 2010), a comunidade Truká da Aldeia-Mãe está situada em uma ilha da margem esquerda do Rio São Francisco, em pleno semiárido nordestino, e compreende a chamada Ilha Grande (Ilha da Assunção) e ilhotas que compõem o Arquipélago da Assunção (BATISTA, 2004). É uma terra indígena com uma secular história documentada, ocupada por um povo indígena com igual tempo de contato com a sociedade não-indígena.

Lugares historicamente idílicos, as ilhas representam não apenas um território delimitado, mas também a segurança da não contaminação sociocultural; objetos que edificam um isolamento que, na contemporaneidade da comunicação imediata e das novas necessidades socioculturais, tornou-se utópico. Então, apesar de aparente isolamento insular, percebe-se claramente que as fronteiras do povo Truká são muito tênues, sejam geográficas ou socioculturais. A figura 1 apresenta o mapa da região e das comunidades Truká: 

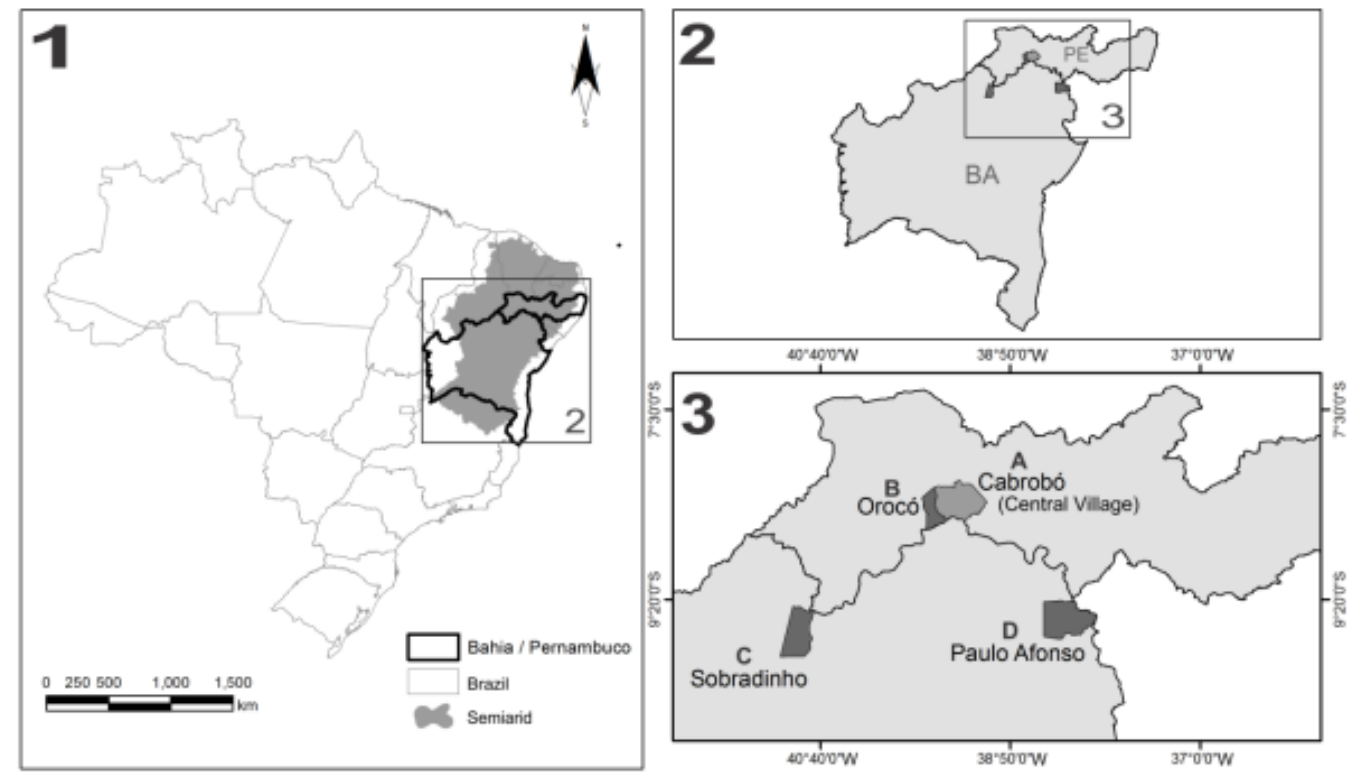

Figura 1: mapas da localização do povo Truká. Fonte: FLORÊNCIO, 2016.

Banhada pelo Rio São Francisco, em um dos lugares mais largos do seu extenso curso, a pequena faixa de terra, desmembrada do "continente" pelas ações naturais e em consonância com ações antrópicas, tem uma natureza exuberante para os padrões de vegetação próprios da caatinga: são arbustos fartamente abastecidos pelas águas do rio, dos lençóis subterrâneos e da irrigação, elemento constante na paisagem atual de Assunção. Por todos os lados da ilha é comum encontrar roçados de cebola, arroz, fruticultura e capim para pasto, todos irrigados por tecnologias de irrigação mais ou menos estruturadas. Ingazeiras (Inga sp), faveleiras (Cnidoscolus quercifolius Pohl) e jatobás (Hymenaea courbarilL.), elementos próprios do bioma, convivem com árvores exóticas como a algaroba (Prosopis juliflora (Sw) DC) e leucena (Leucaena leucocephala (Lam.) de Wit,) e juntos, refazem o que seria a mata ciliar (SANTOS, 2016). Há uma grande área preservada, áreas de sequeiro, além das ruínas do antigo aldeamento, do cemitério indígena e parte da caatinga, que é considerada área sagrada para a comunidade Truká (BATISTA, 2004).

O fato é que as ilhas sempre foram relacionadas a locais idilicos, cenários naturais intocáveis pela sua inacessibilidade e que nos remetem a descrições da literatura, pela presença constante do bucólico e predominância da natureza, se não intocada, mas bastante preservada (FLORÊNCIO, 2016, p. 36).

É isso que ocorre na Ilha da Assunção do Povo Truká: ao cruzar a estreita ponte que liga a pequena cidade de Cabrobó à comunidade indígena, localizada em meio ao semiárido pernambucano, tem-se a sensação de que se adentra um paraíso, tanto pela exuberância da caatinga que ali ganha pequenos contornos de mata, mas também pela abundância aquática. A Ilha Grande ou Ilha da Assunção é, antes de tudo, um locus interessante por diversos aspectos da territorialidade que aqui serão apresentados, divididos em duas delimitações mais comumente perceptíveis no 
contato com os habitantes da Assunção, e servem como referenciais para o entendimento da territorialidade Truká: os aspectos geo-físicos, que coincidem com questões relativas à agricultura, pesca e mercado, e os aspectos mítico-culturais, que, interligados, formam a estrutura sociocultural que fazem o existir Truká (FLORÊNCIO, 2016). Por isso, se necessário o desenvolvimento de estudos que enfatizem os saberes e práticas, bem como dirigir nossa atenção ao conhecimento local, fazendo emergir o universo cultural dos povos indígenas nos sertões nordestinos, focando nas narrativa, simbologias, causos e contos, que descortinam o imaginário popular, aliando sistematização desses saberes à manutenção das culturas locais.

\section{AS OFICINAS}

A turma foi dividida em equipes, cada uma das equipes foi designada para atuar em uma escola ou série, apresentando conteúdos e desenvolvendo atividades pedagógicas no formato de oficinas com os alunos das escolas selecionadas. As atividades foram desenvolvidas no formato de oficinas, sendo assim distribuídas:

Oficina 1: Os usos de ervas medicinais nas culturas indígenas.

Oficina 2: A diversidade dos índios do Nordeste.

Oficina 3: Aspectos culturais dos índios da Bahia - música e vocabulário.

Oficina 4: Elaboração de dicionário indígena e cordel.

Oficina 5: Os mitos, artes e culinária no ensino da história indígena.

Oficina 6: O processo histórico e cultural indígena no contexto da contemporaneidade

As atividades comuns a todas as oficinas foram:

1 - Apresentação do vídeo “Os índios do Brasil”, seguida de discussão em sala de aula, a partir dos questionamentos: Quem são os índios brasileiros? Onde e como vivem?

2 - Estudo e interpretação do texto: “De índios 'misturados' a índios 'regimados”, de Maria Rosário Carvalho.

3 - O ritual do Toré: enfatizando aspectos da espiritualidade indígena.

4 - As oficinas culminaram com a apreciação e análise crítica da canção "Todo dia era dia de índio" (Jorge Benjor), interpretada pela cantora Baby Consuelo (do Brasil).

5 - Confecção de colares e indumentárias indígenas.

6 - Produção de textos sobre a temática educação indígena.

7 - O preconceito que pesa sobre os povos indígenas foi abordado pelo cacique do povo Atikum. 
As atividades desenvolvidas neste projeto tiveram o intuito de contemplar vivências pedagógicas a fim de proporcionar saberes pertinentes ao currículo escolar, às concepções e ações educacionais direcionadas para fomentar na comunidade escolar a (re)construção e valorização da identidade sociocultural, componentes essenciais para a afirmação de ações de fortalecimento dos povos brasileiros.

É salutar destacar que professores-alunos e comunidade escolar demonstraram que as concepções teóricas e metodológicas aplicadas, representaram atividades inéditas desenvolvidas nas escolas com o foco na temática indígena.

\section{CONSIDERAÇÕES FINAIS}

As oficinas proporcionaram a busca e o aprimoramento de práticas pedagógicas específicas, capazes de estabelecer diálogos, ampliar espaços de construções do conhecimento, de colaboração, de construir novas conexões, buscar caminhos alternativos enquanto fontes proporcionando aos alunos conexão com o espaço escolar e com os acontecimentos históricos dos povos indígenas e da sociedade brasileira (FONSECA, 2003). Desta forma, a escola torna-se um espaço de criação de novas possibilidades de reflexão e produção de conhecimento, construindo e adaptando os recursos metodológicos disponíveis ao ensino da Cultura Indígena, facilitando a aprendizagem e apropriação das expressões culturais dos índios do Brasil, em especial, dos índios do sertão nordestino.

As oficinas ocorreram na comunidade da Aldeia-Mãe da Ilha da Assunção, no município de Cabrobó, na Escola Acilon Ciriaco, referenciada pela comunidade por levar o nome de importante liderança indígena assassinada durante os conflitos de terra, no período de retomada do território. O desenvolvimento das oficinas obteve total receptividade por parte dos professores indígenas, tendo em vista que os professores já recebiam formações organizadas pela Gerência Regional de Educação do Estado de Pernambuco, promovidas pela GRE Submédio São Francisco, localizada em Petrolina. Para o aprofundamento da temática escolhida e de vivências de práticas pedagógicas que valorizem a aprendizagem e na construção e afirmação da cidadania, pois, é necessário que os educadores "se preocupem na escola, com a formação de uma consciência social e política dos educandos", isto é, serem capazes de pensarem historicamente" (ZAMBONI, 2003, p. 113).

Pode-se concluir, a partir do relatório oral apresentado pelas equipes na culminância das atividades, que as oficinas atingiram os objetivos propostos, contribuindo para a educação das relações étnicas, com a aplicação de práticas pedagógicas com vistas à valorização da cultura 
indígena e ao reconhecimento da relevância de suas causas sociais. Percebemos que, por parte dos alunos-professores, a atividade conseguiu promover o despertar da convicção de que o tema deve fazer parte da rotina da escola, que novas rotinas escolares devem ser inventadas e que os próprios currículos precisam se renovar a partir da inclusão da temática indígena em sala de aula.

Percebeu-se que os grupos formados pelos professores-alunos utilizaram de diversas estratégias metodológicas para efetivação das Oficinas de Cultura Indígena, sendo de extrema importância para a reflexão do tema nas escolas e pela inclusão de metodologias de ensino até então nunca utilizadas. Recomendamos que as estratégias utilizadas sejam replicadas em outras instituições de ensino e que a história indígena seja vivenciada nos espaços escolares como previsto na lei 11.645/08.

\section{REFERÊNCIAS BIBLIOGRÁFICAS}

ABUD, Kátia Maria. Registros e Representação do Cotidiano: A Música Popular na Aula de História. Cad. Cedes, Campinas, vol. 25, n. 67, p. 309-317, set./dez, 2005. Disponível em www.scielo.br/pdf/ccedes/v25n67/a04v2567.pdf. Acessado em 20/06/2012.

BATISTA, M. R. R. 2004. O desencantamento da aldeia. Exercício antropológico a partir do Relatório Circunstanciado de Identificação e Delimitação da Terra Indígena Truká. FUNAI, Brasília. Revista Estudos e de Pesquisas. v.1, n. 2, p. 157-247.

BATISTA, M. R. R. (2009). Índio, quilombola, ribeirinho: o desafio do fazer antropológico em situações de disputas. In: VIII Reunión de Antropología del Mercosur (RAM), Buenos Aires, 2009.

BRASIL. 2006. Caderno do Tempo: professoras e professores indígenas de Pernambuco - MEC/SECAD Secretaria de Educação Continuada, Alfabetização e Diversidade. Belo Horizonte.

BRASIL. Ministério da Educação (MEC). Coordenação Geral de Educação Escolar Indígena (SECAD). Meu Povo Conta. Centro de Cultura Luiz Freire. Projeto Educação e Cidadania. Olinda - PE. $2^{a}$. Ed. pp. 95106. 2006.

FLORÊNCIO, Roberto Remígio. Educação e letramento intercultural na aldeia de Assunção do povo Truká. Dissertação de Mestrado. Universidade do Estado da Bahia. Departamento de Ciências Humanas. Programa de Pós-Graduação Mestrado em Educação, Cultura e Territórios Semiáridos - PPGESA, Juazeiro, 2016.

FONSECA, Selma Guimarães. Didática e Prática de Ensino de História. $2^{a}$ Ed. Campinas: Papirus, 2003.

FUNDAÇÃO NACIONAL DO INDIO. Relatório Truká 2011. 2011. Disponível em: < http:/ funaiba-pa.blogspot.com.br/p/blog-page_4167.html>. Acesso em: 11 out. 2012.

GEERTZ, C. A interpretação das culturas. Rio de Janeiro: Zahar, 1978.

IBGE - INSTITUTO BRASILEIRO DE GEOGRAFIA E ESTATÍSTICA. Os Indígenas no Censo

Demográfico 2010: primeiras considerações com base no quesito cor ou raça. Rio de Janeiro: IBGE, 2010.

Disponível em http://www.ibge.gov.br/indigenas/mapas.html. Acesso em 14 fev. 2019.

BITTENCOURT, Circe M. Ensino de História: fundamentos e métodos. São Paulo: Cortez, 2004. 
NAPOLITANO, Marcos. A bistória depois do papel. In: Fontes Históricas. São Paulo: Contexto, 2006.

OLIVEIRA, João Paulo de. (Org.). A viagem de volta: etnicidade, política e reelaboração cultural no Nordeste indígena. 2 ed. Rio de Janeiro: Contra Capa, 2004.

SANTOS, Carlos Alberto Batista. Tese de Doutorado em Etnobiologia e conservação da Natureza. UFRPE, 2016.

SILVA, Edson. "Os Caboclos” Que São Índios: História e Resistência Indígena no Nordeste. Portal do São Francisco - Revista do Centro de Ensino Superior do Vale do São Francisco/CESVASF. Belém de São Francisco, ano III, no. 3, 2004, pp.127-137.

Povos indígenas no Sertão: uma história de esbulhos das terras, conflitos e de mobilização por seus direitos.

Historien - Revista de História. Ano II, [5]. Petrolina, jun./nov. 2011, 139p.

. As Sociodiversidades Indígenas no Currículo Escolar: A LEI 11.645/08. Semana da Consciência

Negra do IF Sertão PE Campus Floresta. Floresta, PE, novembro, 2011.

ZAMBONI, Ernesta. Projeto Pedagógico dos Parâmetros Curriculares Nacionais: Identidade Nacional e Consciência História. In: História e Ensino. Revista do Laboratório de Ensino de História. UEL. V9.

Londrina: Humanidades, 2003. 